\title{
Polydimethylsiloxane Membranes Containing Multi-walled Carbon Nanotubes for Gas Separation
}

\author{
Elisângela Aparecida da Silva ${ }^{a}$, Dario Windmöller ${ }^{b}$, Glaura Goulart Silva ${ }^{b}$,
}

\author{
Kátia Cecília de Souza Figueiredo *
}

\begin{abstract}
${ }^{a}$ Departamento de Engenharia Química, Escola de Engenharia, Universidade Federal de Minas Gerais, Avenida Presidente Antônio Carlos, 6627, Zip code 31270-901, Belo Horizonte, MG, Brazil

${ }^{b}$ Departamento de Química, Instituto de Ciências Exatas, Universidade Federal de Minas Gerais, Avenida Presidente Antônio Carlos, 6627, Zip code 31270-901, Belo Horizonte, MG, Brazil
\end{abstract}

Received: November 05, 2016; Revised: May 28, 2017; Accepted: July 12, 2017

\begin{abstract}
Polydimethylsiloxane (PDMS) membranes with different concentrations of multi-walled carbon nanotubes were prepared in order to evaluate their gas separation performances. Mixed matrix membranes were characterized by scanning electron microscopy, thermogravimetric analysis, Fourier transformed infrared, positron annihilation lifetime and Raman spectroscopies and X-ray diffraction. The permeabilities to $\mathrm{CO}_{2}, \mathrm{CH}_{4}, \mathrm{~N}_{2}$ and $\mathrm{O}_{2}$ were determined. No phase separation was noticed. For carbon nanotubes content of $1 \mathrm{wt} \%$, it was shown a decrease in membrane permeability with slight increase in ideal selectivity, compared to pure PDMS. However, the increase in the filler load up to $6.7 \mathrm{wt} \%$ increased the free volume average size of the membranes, improving the contribution of the diffusion to the transport and decreasing ideal selectivities of $\mathrm{CO}_{2} / \mathrm{CH}_{4}, \mathrm{CO}_{2} / \mathrm{N}_{2}$ and $\mathrm{O}_{2} / \mathrm{N}_{2}$.
\end{abstract}

Keywords: carbon dioxide, gas separation, mixed matrix membranes, multi-walled carbon nanotubes, polydimethylsiloxane

\section{Introduction}

The use of synthetic membranes for gas separation reached an industrial level in the 1980s. The gas mixtures processed by this technology were $\mathrm{O}_{2} / \mathrm{N}_{2}, \mathrm{H}_{2} / \mathrm{N}_{2}, \mathrm{H}_{2} / \mathrm{CH}_{4}$ and $\mathrm{CO}_{2} / \mathrm{CH}_{4}$, this last one regarded to natural gas separation ${ }^{1}$. However, ordinary membranes show a trade-off behavior between permeability and selectivity, as reported by Robeson ${ }^{2,3}$. In order to circumvent such limitation, mixed matrix membranes have been investigated as an alternative aiming the increase in both permeability, which allows high productivity, and selectivity, leading to the improvement of process yield ${ }^{4}$.

Mixed matrix membranes can be defined as the combination of two main materials: a solid (dispersed) phase and a polymeric continuous one. The objective is the use of the solid phase in order to overcome the trade-off behavior reported by Robeson ${ }^{4}$. However, there are still some issues that remain unsolved in order to launch the technology, such as the material compatibility regarding their permeabilities, particle size to prepare a thin membrane and optimization of the contact between the two phases, for instance ${ }^{4}$.

Carbon nanotubes, CNT, have proven to be a potential solid phase in mixed matrix membranes ${ }^{5}$. Their structure is based on the carbon-carbon bond, arranged in a hexagonal flat ring, similar to graphite, but in tube shape ${ }^{6}$. Both single and multiple-wall carbon nanotubes, SWCNT and MWCNT, respectively, have shown improvements in mechanical properties of membranes, mainly because of their high aspect ratio ${ }^{7}$.

*e-mail: katia@deq.ufmg.br
Molecular dynamics simulation indicated that the transport of light gases in carbon nanotubes is high compared to zeolites, and the diffusion coefficients in CNT are in the same magnitude of the ones in gases, due to the smoothness of their surfaces ${ }^{8}$. Gusev and Guseva developed a coupled-form finite element approach to estimate the transport properties in CNT-filled polymer matrix membranes. The orientation, content and aspect ratio of defect-free open-ended nanotubes were studied and demonstrated that the addition of CNT can improve membrane flux with maintenance of polymer intrinsic selectivity ${ }^{9}$. Specifically, it was shown that the permeability is directly related to the product of CNT aspect ratio and volume fraction up to $400^{9}$.

However, there are significant differences between theoretical and experimental CNT-mixed matrix membranes. The main reasons are the existence of defects in CNT, poreentrance and exit effects, imperfect contact between CNT and polymer interface as well as changes in polymer chain arrangement due to the inorganic filler ${ }^{10,11}$. As the result, the predicted magnitudes of permeabilities were not achieved ${ }^{9}$.

Glassy polymers are usually preferred to the elastomeric ones as matrix for the preparation of CNT-mixed matrix membranes ${ }^{12-17}$. This is due to the high selectivity found for these materials, although the permeability is usually very low. Therefore, the addition of CNT to these high selectivity polymers increased the light gases permeance while the permselectivity remained unchanged ${ }^{12,15-17}$. However, in some cases, it was also reported an increased selectivity ${ }^{13,14}$. 
The preparation of CNT-filled mixed matrix membranes using elastomeric polymers is less investigated in the literature $^{7,18,19}$. Yu and coauthors ${ }^{7}$ investigated the use of Pebax 1657 nanocomposite membranes incorporated with CNT and other fillers. The authors noticed an increase in $\mathrm{CO}_{2}$ permeability with an increase in CNT content up to 5 wt $\%$. The selectivity over $\mathrm{N}_{2}$ and $\mathrm{H}_{2}$ was retained, compared to the membrane with no added filler ${ }^{7}$.

According to Sedlankova and coauthors ${ }^{18}$, the increase in CNT content in ethylene-octene copolymer membranes caused a slight decrease in light gases permeability while the selectivity was not dependable of the filler content. The permeability results indicated that the addition of CNT acted as a barrier to gas permeability, as predicted by Maxwell equation. The ideal selectivities of $\mathrm{CO}_{2} / \mathrm{N}_{2}, \mathrm{H}_{2} / \mathrm{N}_{2}, \mathrm{CO}_{2} / \mathrm{CH}_{4}$, $\mathrm{He} / \mathrm{N}_{2}, \mathrm{CH}_{4} / \mathrm{N}_{2}, \mathrm{O}_{2} / \mathrm{N}_{2}$ and $\mathrm{CO}_{2} / \mathrm{H}_{2}$ were independent on the CNT content. On the other hand, Nour and coauthors ${ }^{19}$ achieved an increase on $\mathrm{H}_{2} / \mathrm{CH}_{4}$ selectivity of $94.8 \%$ by using MWCNT/PDMS membrane with $1 \mathrm{wt} \%$ of the filler. The authors attributed the result to the decrease in the number of $\mathrm{Si}-\mathrm{CH}_{3}$ and $\mathrm{Si}-\mathrm{O}$ bonds and increase in $\mathrm{Si}-\mathrm{C}$ bonds, which decreased $\mathrm{CH}_{4}$ permeation.

Our goal in this paper was the preparation of MWCNT/ PDMS membranes aiming the application in gas separation. PDMS was chosen for its high permeability to gases while the role of MWCNT could act as a barrier to most gases, but also favor the permeabilities of $\mathrm{CO}_{2}$ and or $\mathrm{O}_{2}$ by adding adsorption sites. The MWCNT content was varied from 0 to $6.7 \mathrm{wt} \%$ in order to assess its effect in membrane permeability. Ideal selectivity of $\mathrm{CO}_{2} / \mathrm{CH}_{4}, \mathrm{CO}_{2} / \mathrm{N}_{2}$ and $\mathrm{O}_{2} / \mathrm{N}_{2}$ were calculated. Mixed matrix membranes were characterized regarding the morphological, chemical and transport properties in order to relate membrane structure and performance. To the best of our knowledge, this is the first study related to the permeability of $\mathrm{CO}_{2}, \mathrm{O}_{2}$ and $\mathrm{N}_{2}$ through MWCNT/PDMS membranes.

\section{Materials and Methods}

\subsection{Materials}

Polystic commercial silicone glue with acetic cure (Pulvitec), which is a mixture of methyltriacetoxisilane (up to $5 \mathrm{wt} \%$ ) and ethyltriacetoxisilane (up to $5 \mathrm{wt} \%$ ) as stated by the manufacturer, toluene (Synth) and multiple-wall carbon nanotube, MWCNT, Nanocyl NC7000, with outer diameter of $9.5 \mathrm{~nm}$ and length of $1.5 \mu \mathrm{m}$ (aspect ratio of 157.9), were used in membrane preparation. $\mathrm{N}_{2}, \mathrm{O}_{2}, \mathrm{CH}_{4}$ and $\mathrm{CO}_{2}$ pure gases were supplied from White Martins.

\subsection{Membrane preparation}

MWCNT/PDMS membranes were prepared by varying MWCNT weight content from 0 to $6.7 \%$. PDMS was prepared using 1:3 wt/wt mixture of polymer and toluene.
The mixture was mechanically stirred for $1 \mathrm{~h}$, at $25^{\circ} \mathrm{C}$. MWCNT were dispersed in toluene by means of mechanical stirring for $12 \mathrm{~h}$, in order to facilitate an effective and uniform dispersion of MWCNT within the PDMS viscous solution, and transferred to the PDMS and toluene flask. After homogenization, the mixture was poured to a Teflon plate with masking tape edges, which were used to control the thickness of the films. The film was dried at $25^{\circ} \mathrm{C}$, for $48 \mathrm{~h}$. Solvent evaporation was kept slow to avoid pores in the structure. After this period, the material was placed in an oven for $1 \mathrm{~h}$, at $120^{\circ} \mathrm{C}$. Membranes were stored in a desiccator before use.

\subsection{Membrane characterization}

\subsubsection{Membrane thickness and morphology}

Membrane thickness was determined by means of a micrometer (Mitutoyo). The values were recorded as the average and standard deviations of, at least, 10 different points in the films.

Membrane morphology was investigated by scanning electron microscopy (JEOL JSM - 6360LV), SEM. Samples were covered with gold (Baltec, MD20), attached to the proper stub and images were recorded.

\subsubsection{Infrared spectroscopy}

Fourier transform infrared spectroscopy, FTIR, equipped with attenuated total reflectance sampling device was performed in the Bruker Alpha equipment, with software opus 7.2, resolution of $1 \mathrm{~cm}^{-1}$. Results were reported as the average of 5 scans. Test was performed in order to evaluate the chemical composition of the resulting samples, specially related to the polymer crosslinking.

\subsubsection{Raman spectroscopy}

Micro-Raman characterization was performed using JobinYvon/Horiba, model LabRam HR 800, equipped with helium laser power (wavelength at $633 \mathrm{~nm}, 20 \mathrm{~mW}$ ), and with optical microscope Olympus BX41. The spectra were recorded from 400 to $3000 \mathrm{~cm}^{-1}$, with resolution of $1 \mathrm{~cm}^{-1}$. Results were recorded as average of 4 measurements.

\subsubsection{X-ray diffraction}

X-ray diffraction (XRD) of PDMS and MWCNT/ PDMS membranes were obtained at $25^{\circ} \mathrm{C}$ using a X-ray diffractometer (Rigaku, model Geigerflex). The diffractograms were measured at a scanning speed of $8^{\circ} \cdot \mathrm{min}^{-1}$, by means of a tube voltage of $40 \mathrm{kV}$ and tube current of $30 \mathrm{~mA}$.

\subsubsection{Thermogravimetric analysis}

Thermogravimetric analysis, TGA, was performed in the TA Instruments, TGA 5000 equipment. $8 \mathrm{mg}$ of the sample were transferred to a platinum pan and heated from 30 to $800^{\circ} \mathrm{C}$, at $10^{\circ} \mathrm{C} / \mathrm{min}$, under nitrogen atmosphere, $25 \mathrm{~mL} / \mathrm{min}$. 


\subsubsection{Positron annihilation lifetime spectroscopy}

Positron annihilation lifetime spectroscopy, PALS, was performed as described elsewhere ${ }^{20}$. Briefly, tests were conducted in a conventional fast-fast coincidence system (ORTEC) with temporal resolution of $240 \mathrm{ps}$, given by ${ }^{60} \mathrm{Co}$ prompt curve. The ${ }^{22} \mathrm{Na}$ positron source was sandwiched between two membrane samples with constant temperature of $25^{\circ} \mathrm{C}$.

\subsubsection{Gas permeability}

$\mathrm{N}_{2}, \mathrm{O}_{2}, \mathrm{CO}_{2}$ and $\mathrm{CH}_{4}$ permeabilites in PDMS and MWCNT/ PDMS membranes were determined using the standard apparatus presented in Figure 1 and detailed elsewhere ${ }^{20}$.

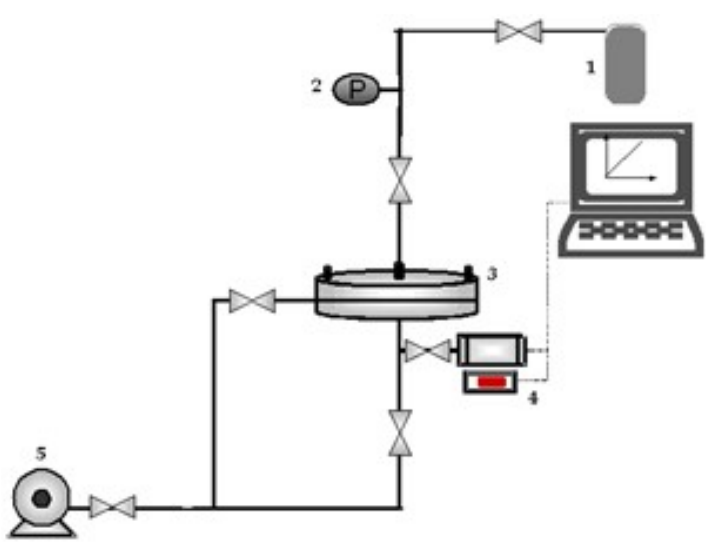

Figure 1. Gas permeation set up. 1- Gas cylinder, 2 - pressure sensor, 3 - permeation cell, 4 - Data log system, 5 - vacuum pump.

The desired gas was fed to the module containing the membrane. As the gas permeated the film, the increase of pressure on the permeate side, which was previously evacuated, was monitored with time. The slope of the curve of pressure versus time in the steady state region was used to calculate membrane permeability, as shown in Equation 1.

$$
P=\frac{133.32 V_{m} V_{c} l}{\left(5.17 p_{u}-0.1 p_{d}\right) R T A}\left(\frac{d p_{d}}{d_{t}}\right)
$$

$P$ is the permeability coefficient, expressed in Barrer $\left(1\right.$ Barrer $\left.=10^{-10} \mathrm{~cm}^{3}(\mathrm{STP}) \cdot \mathrm{cm} /\left(\mathrm{cm}^{2} . \mathrm{s} . \mathrm{cmHg}\right)\right) . \mathrm{V}_{\mathrm{m}}$ and $\mathrm{V}_{\mathrm{c}}$ are the ideal gas molar volume at STP, $0.0224 \mathrm{~m}^{3} / \mathrm{mol}$, and the calibrated volume of the permeate reservoir, in $\mathrm{cm}^{3}$, respectively. $l$ is the membrane thickness, in $\mathrm{cm}, \mathrm{p}_{\mathrm{u}}$ and $\mathrm{p}_{\mathrm{d}}$ are the upstream and downstream pressures, in psi and torr, respectively. $p_{u}$ was maintained at 14 psi in all measurements. $\mathrm{R}$ is the universal gas constant, $\mathrm{T}$ is the operating temperature, $298 \mathrm{~K}$, and $\mathrm{A}$ is membrane area, in $\mathrm{cm}^{2}$. The ratio $\mathrm{dp}_{\mathrm{d}} / \mathrm{dt}$ is the slope of the curve, regarding to the increase in downstream pressure with time. The ideal selectivity of one pair of gases was calculated as the ratio of their permeabilities.

\section{Results and Discussions}

\subsection{Multi-walled carbon nanotubes}

Characterization tests were performed in order to confirm the MWCNT properties informed by Nanocyl, such as thermogravimetric analysis, specific surface area and transmission electron microscopy. All the evaluated properties were in accordance with the manufacturer. It is worth noting that the sample showed $89 \%$ purity and a specific area of $291 \mathrm{~m}^{2} / \mathrm{g}$. The aspect ratio was evaluated by means of TEM. The remaining $11 \mathrm{wt} \%$ of CNT in thermogravimetric analysis was attributed to the metal oxide used as catalyst in the synthesis.

\subsection{Membrane thickness and morphology}

Homogeneous and defect-free membranes were prepared. Membrane average thickness ranged from 142 to $280 \mu \mathrm{m}$, as shown in Table 1, with standard deviation lower than $1 \%$. This broad range was due to the amount of suspension cast in the plate and no relation could be found between membrane thickness and the MWCNT content. However, MWCNT load was varied from 0 to $10 \mathrm{wt} \%$, but this last content did not allow the formation of a dense film. The higher MWCNT concentration in which a good film could be formed was $6.7 \mathrm{wt} \%$.

Table 1. Membrane thickness as a function of MWCNT content.

\begin{tabular}{lc}
\hline MWCNT (wt\%) & Thickness (mm) \\
\hline 0 & $204 \pm 2$ \\
1.0 & $173 \pm 1$ \\
3.0 & $142 \pm 1$ \\
6.7 & $280 \pm 3$ \\
\hline
\end{tabular}

SEM images of the MWCNT/PDMS top surface membranes are presented in Figure 2. The images were typical of PDMS films, in which a roughness surface was observed. No differences were noticed among the images due to the MWCNT content of samples.

\subsection{Infrared and Raman spectroscopy}

FTIR spectra of PDMS and MWCNT/PDMS membranes are shown in Figure 3. No markedly difference was noticed in the spectra as a function of MWCNT content. Some interesting findings were the absence of absorption bands around $3300 \mathrm{~cm}^{-1}$ and $1700 \mathrm{~cm}^{-1}$, which are typical of hydroxyl and carbonyl groups, respectively, as would be expected for silicone with acetic cure, indicating that the acetic acid was completely removed during membrane formation, probably in the thermal treatment step. On the other hand, bands from 


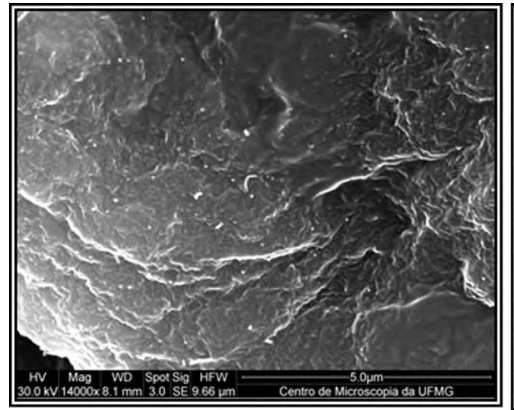

a

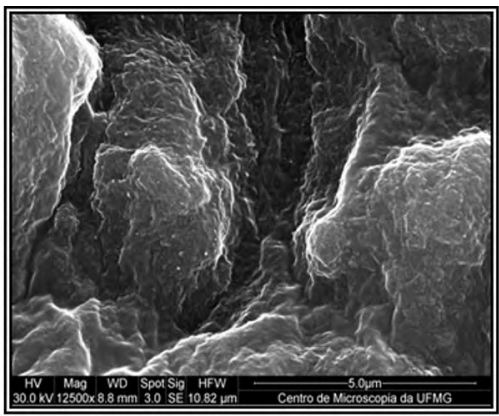

b

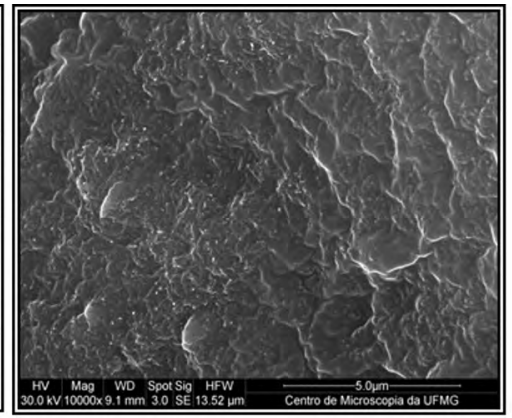

c

Figure 2. SEM images of MWCNT/PDMS membranes. MWCNT content: (a) $1 w t \%$, (b) $3 w t \%$ and (c) $6.7 \mathrm{wt} \%$.

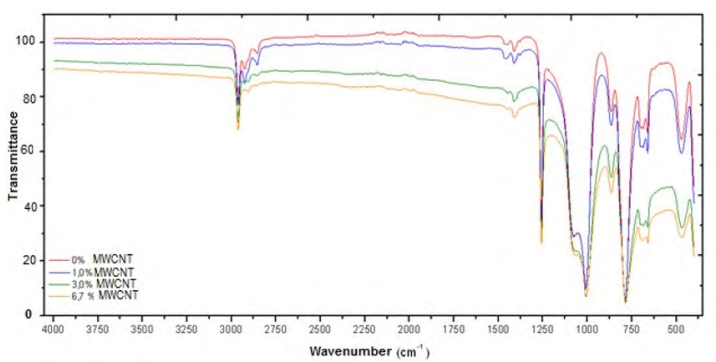

Figure 3. FTIR spectra of PDMS and MWCNT/PDMS membranes.

2852 to $2962 \mathrm{~cm}^{-1}$ related to C-H stretching of the $\mathrm{sp}^{3}$ carbon and also bands at 1412 and $1258 \mathrm{~cm}^{-1}$, usually related to the stretching of $\mathrm{C}-\mathrm{H}$ of $-\mathrm{Si}\left(\mathrm{CH}_{3}\right)_{2}-$ groups were noticed. Two overlapping bands at 1007 and $1074 \mathrm{~cm}^{-1}$ were also noticed and are usually caused by the stretching of Si-O-Si from the main chain of PDMS. The Si-C stretching bands and $\mathrm{Si}-\left(\mathrm{CH}_{3}\right)_{2}$ rocking peaks were observed at $825-865$ and $785-815 \mathrm{~cm}^{-1}$, respectively. It is also worth noting that no evidence of residual solvent (toluene) was noticed.

Micro-Raman spectra of PDMS and MWCNT/PDMS membranes are presented in Figure 4. It was noticed a symmetric $\mathrm{Si}-\mathrm{O}-\mathrm{Si}$ peak around $488 \mathrm{~cm}^{-1}$. The $\mathrm{Si}-\mathrm{CH}_{3}$ symmetric rocking peak was shown at $615 \mathrm{~cm}^{-1}$. At $707 \mathrm{~cm}^{-1}$, the $\mathrm{Si}-\mathrm{C}$ symmetric stretching band was noticed. The peaks of the symmetric bending, symmetric and asymmetric rocking of $-\mathrm{CH}_{3}$ were shown at 787, 856 and $1257 \mathrm{~cm}^{-1}$, respectively. The $\mathrm{Si}-\mathrm{CH}_{3}$ symmetric and asymmetric stretching bands were at 2902 and $2904 \mathrm{~cm}^{-1}$. Regarding de MWCNT, both the D and G bands, around $1330 \mathrm{~cm}^{-1}$ and $1605 \mathrm{~cm}^{-1}$, could be clearly seen ${ }^{17,19}$. G' corresponding band, at $2650 \mathrm{~cm}^{-1}$, was noticed. It is worth noting that $\mathrm{D}$ band is observed when there are symmetrical breaking of the $\mathrm{sp}^{2}$ bonding lattices located in the edge site and defects of the graphite network. In our case, the choice of a relatively short CNT was based on the effect of the aspect ratio of the nanotubes in permeability ${ }^{9}$. As the result of increasing MWCNT content, the bands typical of the solid phase increase, while the ones related to the PDMS content decreased.

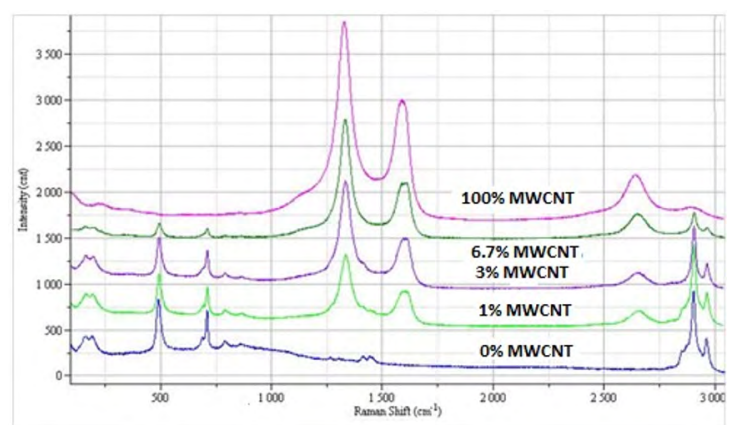

Figure 4. Micro-Raman spectra of PDMS and MWCNT/PDMS membranes.

\section{$3.4 X$-ray diffraction}

XRD results of PDMS and MWCNT/PDMS membranes are shown in Figure 5. The addition of MWCNT did not change PDMS standard XRD profile. The amorphous halo, at $2 \theta=12.5^{\circ}$, was typical of the XRD pattern of PDMS, indicating that the addition of MWCNT did not increase the crystalline domain of the films. It is worth noting that the decrease in the amorphous degree of membranes is usually associated to a lower effective area for permeation, since the crystals are very impermeable.

\subsection{Thermogravimetric analysis}

TG curves of PDMS and MWCNT/PDMS membranes are presented in Figure 6 . The curves followed the typical pattern of polydimethylsiloxane: an initial weight loss at about $400^{\circ} \mathrm{C}$ related to the exit of the lateral groups from the main chain, followed by a slight change on weight loss rate at about $500^{\circ} \mathrm{C}$, usually ascribed to the degradation of the main chain of siloxane. Regarding the MWCNT, there are 3 weight loss stages: the first usually associated to adsorbed apolar gases, the second regarded to the decomposition of functional groups and the final one, at higher temperatures, due oxidation of CNTs.

The results showed that PDMS profile governed the thermal decomposition. The addition of MWCNT slightly increased the thermal resistance of the membranes, indicating 


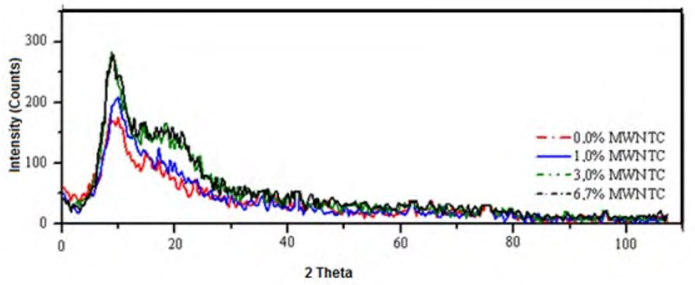

Figure 5. XRD curves of PDMS and MWCNT/PDMS membranes.

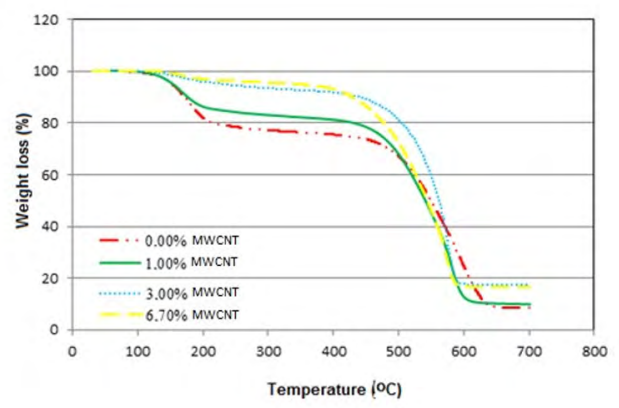

Figure 6. TG curves of PDMS and MWCNT/PDMS membranes.

that some molecular rearrangement on PDMS chains could be noticed. Two main weight loss stages were observed: the loss of volatile compounds and the degradation of polymer and CNT. The loss of volatile compounds, around $150^{\circ} \mathrm{C}$, decreased with the increase in MWCNT content. These volatile substances, which varied from 5 to $25 \mathrm{wt} \%$, are probably related to the adsorption of gases and vapor of apolar molecules on membrane surface. The main weight loss stage, regarded to the degradation of both PDMS and MWCNT, was started at around $450^{\circ} \mathrm{C}$. The highest weight loss rate was noticed at $596^{\circ} \mathrm{C}$, in accordance to the result for MWCNT.

\subsection{Positron annihilation lifetime spectroscopy}

The results of PALS measurements, i. e., $\tau_{3}$ and $I_{3}$, the average size of free volume cavities and the free volume concentration, respectively, for PDMS and MWCNT/PDMS membranes are presented in Figure 7. They showed different behaviors. $I_{3}$ decreased with the increase in MWCNT content in the PDMS, while $\tau_{3}$ remained almost constant for lower MWCNT content up to $3.0 \mathrm{wt} \%$ and showed a markedly increase for the sample with $6.7 \mathrm{wt} \%$. This was the evidence that the addition of MWCNT changed the PDMS chain arrangement. Although the increase in MWCNT content from 1 to $6.7 \mathrm{wt} \%$ caused an increase in membrane free volume fraction, the concentration of the cavities decreased significantly.

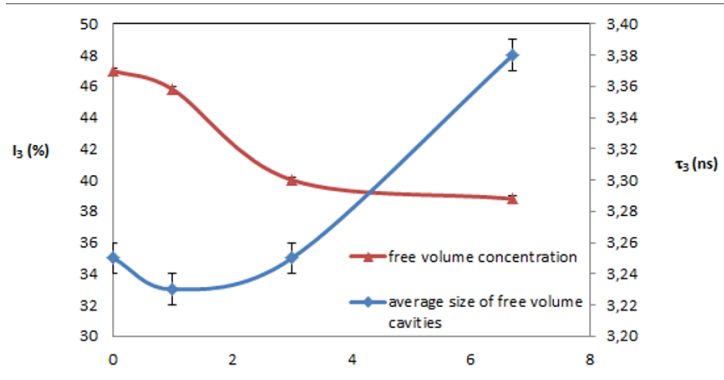

Figure 7. PALS measurements of PDMS and MWCNT/PDMS membranes. Triangle: $\tau_{3}(\mathrm{~ns})$; Diamond: $\mathrm{I}_{3}(\%)$. Error bar are the deviations of 3 different readings.

\subsection{Transport properties}

Figure 8 and Table 2 show gas permeability and selectivity of PDMS and MWCNT/PDMS membranes, respectively. Deviations in membrane permeability were lower than $5 \%$ and were not added to the Figure to allow clearance.

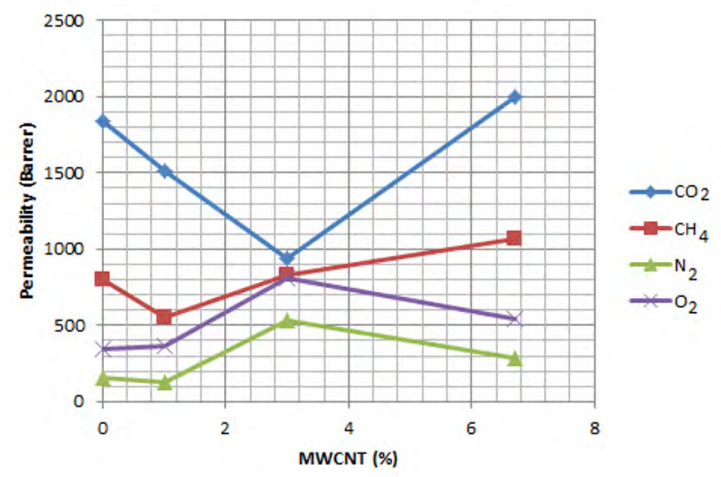

Figure 8. Gas permeability for PDMS and MWCNT/PDMS membranes.

Table 2. Ideal selectivity for PDMS and MWCNT/PDMS membranes.

\begin{tabular}{lccc}
\hline MWCNT (wt\%) & $\mathrm{CO}_{2} / \mathrm{CH}_{4}$ & $\mathrm{CO}_{2} / \mathrm{N}_{2}$ & $\mathrm{O}_{2} / \mathrm{N}_{2}$ \\
\hline 0 & 2.31 & 11.54 & 2.17 \\
1.0 & 2.73 & 11.83 & 2.81 \\
3.0 & 1.71 & 2.10 & 1.39 \\
6.7 & 1.90 & 6.92 & 1.86 \\
\hline
\end{tabular}

Permeabilities were mainly governed by the sorption of penetrants, since it was higher for $\mathrm{CO}_{2}$, followed by $\mathrm{CH}_{4}, \mathrm{O}_{2}$ and $\mathrm{N}_{2}$, directly related to the critical temperature (condensability) of gases; which is in accordance with the literature for similar system (carbon nanotubes/ elastomeric ethylene-octene copolymer ${ }^{18}$. This result revealed that the chain modifications of PDMS caused by the introduction of MWCNT were not high enough to modify the permeability sequence of the tested gases. 
The higher permeability was noticed for $\mathrm{CO}_{2}$, which is particular interesting upon considering the separation $\mathrm{CO}_{2} / \mathrm{CH}_{4}$ in natural gas, in which $\mathrm{CO}_{2}$ content is lower than $\mathrm{CH}_{4}$. This behavior was expected in ordinary films because $\mathrm{CO}_{2}$ shows the highest condensability and the lowest kinetic diameter compared to the other gases, which means that its transport is favored both for sorption and diffusion-governed systems. It is also worth noting that $\mathrm{CO}_{2}$ permeability reached in this paper was higher than similar systems in the literature ${ }^{7,18}$, in which other elastomeric polymers with lower free volume fraction compared to PDMS were investigated, but it was in the same magnitude of non-loaded PDMS $^{21}$.

Regarding the MWCNT content, the highest permeability to $\mathrm{CO}_{2}$ and $\mathrm{CH}_{4}$ was observed for the $6.7 \mathrm{wt} \% \mathrm{MWCNT} /$ PDMS membrane. The behavior of $\mathrm{CO}_{2}$ transport was already explained, since it is the more condensable gas and the most favored specie for diffusion. As the result, the increase in membrane average size of free volume cavities $\left(\tau_{3}\right)$ for $6.7 \mathrm{wt} \%$ of MWCNT increased the diffusion effect of $\mathrm{CO}_{2}$. For $\mathrm{CH}_{4}$, the highest free volume size observed at $6.7 \mathrm{wt} \%$ caused an increase in $33 \%$ on membrane permeability, compared to non-loaded PDMS, even to the highest molecule (kinetic diameter $=3.8 \AA$ ) and considering the decrease in free volume concentration. On the other hand, $\mathrm{O}_{2}$ and $\mathrm{N}_{2}$ permeabilities varied in a much less extent with the addition of MWCNT in the PDMS membrane, with maximum permeability at $3 \mathrm{wt} \%$ MWCNT, possibly indicating that a slight increase in $\tau_{3}$, lower than the precision of our measurement, caused an increase in transport due to diffusion for the second and third lower gases (kinetic diameters of 3.46 and $3.64 \AA$ for $\mathrm{O}_{2}$ and $\mathrm{N}_{2}$, respectively). It is worth noting that the ratio in $\mathrm{N}_{2}$ and $\mathrm{O}_{2}$ permeabilities of $3 \mathrm{wt} \%$ MWCNT related to pure PDMS were 3.3 and 2.3, respectively.

As a general behavior, it was noticed that the addition of $1 \mathrm{wt} \%$ of MWCNT to PDMS caused a decrease in gas transport, so that the filler acted as a barrier to permeation, as predicted by Maxwell model ${ }^{18}$. On the other hand, the use of higher CNT contents ( 3 and $6.7 \mathrm{wt} \%$ ) increased membrane average size of free volume cavities, resulting in higher permeabilities due to the diffusion contribution to the transport.

In general, membrane ideal selectivity to the gas pairs of industrial interest was very low, far from the Robeson curve, which represents the higher permeability and selectivity ordinary materials ${ }^{3}$. The highest selectivity was found for membranes with MWCNT content of $1 \mathrm{wt} \%$, in which the addition of carbon nanotubes seemed to act like a barrier to gas permeation, decreasing both average size of free volume cavities and concentration. This could be reasoned in terms of the little effect of $1 \mathrm{wt} \%$ nanotubes in PDMS transport properties (specially sorption), as consequence of lower effects in $\tau_{3}$ and $\mathrm{I}_{3}$.
It is worth noting that the selectivity found for MWCNT $6.7 \mathrm{wt} \%$ membrane was lower than the one for pure PDMS, which can be ascribed to the increased average size of free volume cavities of the films, which caused the increase on the contribution of diffusion in different manners, related to the size of permeants.

The aforementioned results show that MWCNT/ PDMS system can be used in some specific applications of membrane gas separation, specially as the pre-treatment of plants with high feed rates required. This was related to the high permeability of PDMS, but the increase in membrane ideal selectivity for $\mathrm{CO}_{2} / \mathrm{CH}_{4}$ in MWCNT content of $1 \mathrm{wt} \%$ can improve the process econimcs and make it feasible. Unfortunately, the $\mathrm{O}_{2} / \mathrm{N}_{2}$ separation by MWCNT/PDMS membranes is still very hard to attain.

\section{Conclusions}

The addition of MWCNT to PDMS membranes showed different effects on membrane properties, depending on the filler content. Although the transport was mainly governed by sorption, low nanotubes load caused a decrease in membrane free volume fraction, with increased selectivity. For MWCNT contents higher than $3 \mathrm{wt} \%$, the increase in membrane average size of free volume cavities caused an increase in permeability, with decrease of selectivity. The results showed that the addition of MWCNT can be used to customize membrane free volume fraction by modulating, in a limited extension, the diffusion contribution to the transport, even as a secondary effect. Although the low increase in selectivity have been noticed for $1 \mathrm{wt} \%$ of MWCNT, it should be considered for specific applications, since PDMS is one of the most permeable polymers.

\section{Acknowledgments}

The authors are grateful to Prof. Paulo Roberto Brandão (Departamento de Engenharia de Minas/EE/UFMG), Profa. Virgínia Sampaio Teixeira Ciminelli and Cláudia Caldeira (Departamento de Engenharia Metalúrgica/EE/UFMG), Prof. Wagner Reis da Costa Campos (CDTN/UFMG), Profa. Maria Irene Yoshida (Departamento de Química, ICEx/ UFMG), Conselho Nacional de Desenvolvimento Científico e Tecnológico (455330/2014-0) and Centro de Microscopia da UFMG. Elisângela Silva thanks to Coordenação de Aperfeiçoamento de Pessoal do Ensino Superior, Capes, for the scholarship supplied.

\section{References}

1. Baker RW. Membrane Technology and Applications. 3rd ed. Hoboken: John Wiley \& Sons; 2012. 
2. Robeson LM. Correlation of separation factor versus permeability for polymeric membranes. Journal of Membrane Science. 1991;62(2):165-185. DOI: 10.1016/0376-7388(91)80060-J

3. Robeson LM. The upper bound revisited. Journal of Membrane Science. 2008;320(1-2):390-400. DOI: 10.1016/j. memsci.2008.04.030

4. Noble RD. Perspectives on mixed matrix membranes. Journal of Membrane Science. 2011;378(1-2):393-397. DOI: 10.1016/j. memsci.2011.05.031

5. Ismail AF, Goh PS, Sanip SM, Aziz M. Transport and separation properties of carbon nanotube-mixed matrix membrane. Separation and Purification Technology. 2009;70(1):12-26. DOI: 10.1016/j.seppur.2009.09.002

6. Britz DA, Khlobystov AN. Noncovalent interactions of molecules with single walled carbon nanotubes. Chemical Society Reviews. 2006;35(7):637-659. DOI: 10.1039/b507451g

7. Yu B, Cong H, Li Z, Tang J, Zhao XS. Pebax-1657 nanocomposite membranes incorporated with nanoparticles/colloids/carbon nanotubes for $\mathrm{CO} 2 / \mathrm{N} 2$ and $\mathrm{CO} 2 / \mathrm{H} 2$ separation. Journal of Applied Polymer Science. 2013;130(4):2867-2876. DOI: 10.1002/app.39500

8. Skoulidas AI, Ackerman DM, Johnson JK, Sholl DS. Rapid transport of gases in carbon nanotubes. Physical Review Letters. 2002;89(18):185901. DOI: 10.1103/ PhysRevLett.89.185901

9. Gusev AA, Guseva O. Rapid Mass Transport in Mixed Matrix Nanotube/Polymer Membranes. Advanced Materials. 2007;19(18):2672-2676. DOI: 10.1002/adma.200602018

10. Merkel TC, Freeman BD, Spontak RJ, He Z, Pinnau I, Meakin $\mathrm{P}$, et al. Ultrapermeable, reverse-selective nanocomposite membranes. Science. 2002;296(5567):519-522. DOI: 10.1126/ science. 1069580

11. Merkel TC, He Z, Pinnau I, Freeman BD, Meakin P, Hill AJ. Effect of Nanoparticles on Gas Sorption and Transport in Poly(1trimethylsilyl-1-propyne). Macromolecules. 2003;36(18):68446855. DOI: $10.1021 / \mathrm{ma} 0341566$

12. Cong H, Zhang J, Radosz M, Shen Y. Carbon nanotube composite membranes of brominated poly(2,6-diphenyl-1,4-phenylene oxide) for gas separation. Journal of Membrane Science. 2007;294(1-2):178-185. DOI: 10.1016/j.memsci.2007.02.035
13. Kim S, Chen L, Johnson JK, Marand E. Polysulfone and functionalized carbon nanotube mixed matrix membranes for gas separation: Theory and experiment. Journal of Membrane Science. 2007;294(1-2):147-158. DOI: 10.1016/j.memsci.2007.02.028

14. Sanip SM, Ismail AF, Goh PS, Soga T, Tanemura M, Yasuhiko H. Gas separation properties of functionalized carbon nanotubes mixed matrix membranes. Separation and Purification Technology. 2011;78(2):208-213. DOI: 10.1016/j.seppur.2011.02.003

15. Khan MM, Filiz V, Bengtson G, Shishatskiy S, Rahman MM, Lillepaerg J, et al. Enhanced permeability by fabricating mixed matrix membranes of functionalized multiwalled carbon nanotubes and polymers of intrinsic microporisity (PIM). Journal of Membrane Science. 2013;436:109-120. DOI: 10.1016/j. memsci.2013.02.032

16. Ismail AF, Rahim NH, Mustafa A, Matsuura T, $\mathrm{Ng} \mathrm{BC}$, Abdullah S. et al. Gas separation performance of polyethersulfone/multiwalled carbon nanotubes mixed matrix membranes. Separation and Purification Technology. 2011;80(1):20-31. DOI: 10.1016/j. seppur.2011.03.031

17. Goh PS, Ng BC, Ismail AF, Aziz M, Hayashi Y. Pre-treatment of multi-walled carbon nanotubes for polyetherimide mixed matrix hollow fiber membranes. Journal of Colloid and Interface Science. 2012;386(1):80-87. DOI: 10.1016/j.jcis.2012.07.033

18. Sedláková Z, Clarizia G, Bernardo P, Jansen JC, Slobodian P, Svoboda $\mathrm{P}$, et al. Carbon nanotube- and carbon fiber-reinforcement of ethylene-octene copolymer membranes for gas and vapor separation. Membranes (Basel). 2014;4(1):20-39. DOI: 10.3390/ membranes 4010020

19. Nour M, Berean K, Balendhran S, Ou JZ, Du Plessis J, McSweeney $\mathrm{C}$, et al. CNT/PDMS composite membranes for $\mathrm{H} 2$ and $\mathrm{CH} 4$ gas separation. International Journal of Hydrogen Energy. 2013;38(25):10494-10501. DOI: 10.1016/j.ijhydene.2013.05.162

20. Sales JA, Patrício PSO, Machado JC, Silva GG, Windmöller D. Systematic investigation of the effects of temperature and pressure on gas transport through polyurethane/poly(methylmethacrylate) phase separated blends. Journal of Membrane Science. 2008;310(1-2):129-140. DOI: 10.1016/j.memsci.2007.10.045

21. Yampolskii Y, Pinnau I, Freeman BD, eds. Materials Science of Membranes for Gas and Vapor Separation. Hoboken: John Wiley \& Sons; 2006. 